\title{
Chemical and electrochemical oxidation of C8-arylamine adducts of 2'-deoxyguanosine
}

\author{
James S. Stover, Madalina Ciobanu, David E. Cliffel ${ }^{\star}$, and Carmelo J. Rizzo \\ Department of Chemistry, Center in Molecular Toxicology and Vanderbilt Institute of Chemical \\ Biology, Vanderbilt University, VU Station B 351822, Nashville, TN, 37235-1822
}

\begin{abstract}
The electrochemical and chemical oxidation of a series of C8-arylamine adducts of 2'deoxyguanosine has been examined. The oxidations were found to be reversible by cyclic and squarewave voltammetry in both aqueous buffer and aprotic organic solvent. The mechanism of the oxidation in protic media was either one- or two-electron depending on the aryl group. The chemical oxidation resulted in guanidinohydantoin and spiroiminodihydantoin rearrangement products similar to those observed for 8-oxo-7,8-dihydro-2'-deoxyguanosine.
\end{abstract}

\section{Keywords}

redox potential; $\mathrm{C} 8$-arylamine adduct; deoxyguanosine; food mutagen; electrochemical oxidation; electron transfer; 7,8-dihydro-8-oxo-2'-deoxyguanosine; 2-amino-3-methylimidazo[4,5-f]quinoline (IQ); 2-aminofluorene; 4-aminobiphenyl

\section{Introduction}

Over fifty modified bases have been identified from the oxidation of DNA. ${ }^{1-6}$ The most prevalent of these is 7,8-dihydro-8-oxo-2'-deoxyguanosine (8-oxo-dG). 8-Oxo-dG gives rise to $\mathrm{G} \rightarrow \mathrm{T}$ transversions when processed by replicative DNA polymerases. ${ }^{7}$ This is likely to occur through a syn conformation with the Hoogsteen edge of 8-oxo-dG instructing for dA. 8-10 The trans-lesion polymerase pol $\eta$ has been shown to give largely error-free bypass of 8oxo-dG. ${ }^{11}$

Guanine is the most susceptible of the DNA bases to oxidation. However, the oxidation potential of 8-oxo-dG is $\sim 0.5 \mathrm{~V}$ lower than that of guanosine. This has lead to the hypothesis that 8-oxo-dG may be sensitive to further oxidation and that its oxidation products may play a role in the biology of oxidative damage to DNA. Of particular interest are the spiroiminodihydantoin (2) and the guanidinohydantoin (3) products (Scheme 1), which are derived from two-electron oxidation of 8-oxo-dG and rearrangement. Numerous oxidants are able to convert dG or 8-oxo-dG to these products including peroxynitrate, ${ }^{12}$ carbonate radical, 13,14 singlet oxygen, ${ }^{15}$ hypochlorous acid, ${ }^{16}$ and high valent metal ions such as $\mathrm{Cr}(\mathrm{IV})$ and $\operatorname{Ir}(\mathrm{IV}) .{ }^{17,18}$ Two damaging events occurring at the same site in the genome appears to be highly unlikely. It has been proposed that 8-oxo-dG could act as a sink for one-electron oxidation through a long-distance electron transfer pathway. ${ }^{19}$ In this scenario, the oxidation of DNA occurs at a dG residue creating a cation radical. Because of the large difference in redox potential between $\mathrm{dG}$ and 8-oxo-dG $(\sim 0.5 \mathrm{~V})$, an electron could be transferred from 8-

*Corresponding author: Prof. Carmelo J. Rizzo, Department of Chemistry, Vanderbilt University, VU Station B 351822, Nashville, TN 37235-1822, Telephone: 615-322-6100, FAX: 615-343-1234, Email: c.j.rizzo@vanderbilt.edu. 
oxo-dG to a guanine cation radical. The $0.5 \mathrm{~V}$ difference in oxidation potential represents a driving force for electron transfer of approximate $13 \mathrm{kcal} / \mathrm{mol}$.

The mechanism for the oxidation of 8-oxo-dG to spiroiminodihydantoin (2) and guanidinohydantoin (3) is shown in Scheme 1 and is based on the oxidation of uric acid to 5hydroxyisourate by urate oxidase. ${ }^{4,20,21}$ Burrows demonstrated that this oxidation could be conveniently affected at the nucleoside and oligonucleotide levels with $\mathrm{Na}_{2} \mathrm{IrCl}_{6} \cdot{ }^{18} \mathrm{In}$ oligonucleotides, the oxidation is selective for 8-oxo-dG over the other natural bases. It was discovered that the product distribution between $\mathbf{2}$ and $\mathbf{3}$ in single stranded oligonucleotides could be controlled by temperature. Oxidation at $50^{\circ} \mathrm{C}$ gave $\mathbf{2}$ while 3 was obtained at $4^{\circ} \mathrm{C}$, 22 providing a convenient method for the site-specific incorporation of $\mathbf{2}$ and $\mathbf{3}$ into oligonucleotides in order to examine their biological processing.

8-Oxo-dG as well as many other oxidative lesions are repaired by base excision repair (BER) pathways. Some BER glycosylases also excise the spiroiminodihydantoin (2) and guanidinohydantoin (3) lesions. ${ }^{23-25}$ The spiroiminodihydantoin (2) adducts have been observed from the DNA of chromate-treated E. coli that were deficient in the BER glycosylase Nei. ${ }^{26}$ The human analog to Nei, NEIL1 has also been shown to excise 2 , although the activity of NEIL 2 was low. ${ }^{25}$ In vitro and in vivo replication studies of $\mathbf{2}$ and $\mathbf{3}$ have also been reported. 6,22,27-29 The spiroiminodihydantoin (2) stereoisomers are strong block to replication; however, when they are bypassed they are highly miscoding giving $\mathrm{G} \rightarrow \mathrm{C}$ and $\mathrm{G} \rightarrow \mathrm{T}$ transversions; the relative ratio of these mutations were dependent on the stereochemistry of the spirocyclic base. ${ }^{29,30}$ The guanidinohydantoin (3) adduct was more efficiently bypassed than $\mathbf{2}$ and was also highly miscoding, giving exclusively $\mathrm{G} \rightarrow \mathrm{C}$ transversions. When bypassed, $\mathbf{2}$ and $\mathbf{3}$ are absolutely mutagenic in E. coli. Recent molecular modeling studies of the spiroiminodihydantoin adducts in duplex DNA may provide insight to the biological processing of these lesions by DNA repair and replication proteins. 31,32

C8-Deoxyguanosine adducts of simple arylamines can also undergo oxidative rearrangement to give a spiroiminodihydantoin and guanidinohydantoin modified bases ( $\mathbf{4}$ and $\mathbf{5}$, Scheme 2 ), which are structurally related to those derived from 8-oxo-dG $(2$ and 3$){ }^{33-35}$ The oxidation of the $\mathrm{C} 8$-arylamine adducts has been reported to occur under aerobic conditions at basic $\mathrm{pH}$. No rearrangement products were observed under anaerobic conditions or when thiols were added. The structures of the rearrangement products were confirmed by $\mathrm{x}$-ray crystallography. 35

Arylamines are potent bacterial mutagens and animal carcinogens. ${ }^{36,37}$ All arylamines require a two-stage bioactivations before they can react with DNA. This involves an initial $\mathrm{N}$-oxidation by a cytochrome $\mathrm{P} 450$ followed by esterification of the hydroxylamine by $\mathrm{N}$-acetyltransferase or sulfotranserase enzyme. ${ }^{38}$ Subsequent sovolysis of the hydroxylamine ester gives an arylnitrenium ion, which is the DNA modifying agent. Most arylnitrenium ions preferentially react with DNA at the C8-position of dG; minor C8-dA and $N^{2}$-dG adducts have also been identified in some cases. In bacterial assays, arylamines induce one- and two-base frameshift deletions in reiterated sequences; however, base-pair substitution is the predominant mutation observed in mammalian cells. Given the mutagenic properties of $\mathbf{2}$ and $\mathbf{3}$, related oxidative rearrangement products of $\mathrm{C} 8$-arylamine adducts are likely to be highly miscoding as well.

Exposure to simple aromatic amines can come from a variety of sources. $o$-Toluidine and 4aminobiphenyl are present in cigarette smoke and have been shown to cause tumors in laboratory animals. ${ }^{39}$ 4-Aminobiphenyl is also present in permanent hair dye products. 40 Perhaps the most extensively studied aromatic amines are 2-aminofluorene (AF) and $\mathrm{N}$ acetyl-2-aminofluorene (AAF), which were originally developed as pesticides but never used as intended because they were found to be potent animal carcinogens. 36 Of particular interest 
is a growing class of heteroaromatic amines derived from the pyrolysis of amino acids and sugars and found in cooked meats. ${ }^{41-43}$ Some of these heteroaromatics amines such as 2amino-3-methylimidazo[4,5-f]quinoline (IQ) and 2-amino-1-methyl-6-phenylimidazo[4,5-b] pyridine (PhIP), are potent inducers of two-base frameshift mutations in Ames assays. 44

Electrochemistry has been used to study the oxidation of DNA and its bases. Bard et al. reported recently the electrochemical detection of the guanosine radical cation. ${ }^{45}$ Goyal et al. have investigated the electrochemical oxidation of guanosine-5'-monophosphate at a graphite electrode. ${ }^{46}$ Oliveira Brett et al. showed that the oxidation of 8-oxoguanine at a glassy carbon electrode is a diffusion-controlled quasi-reversible process. 47 -oxo-dG was also studied electrochemically, and Langmaier et al. compared different electrode materials for its electrochemical oxidation and concluded that the rate of the charge transfer reaction is higher at glassy carbon versus other materials $\left(\mathrm{Au}, \mathrm{Pt}, \mathrm{SnO}_{2}\right) .48$ Electrochemical detection of 8-oxo$\mathrm{dG}$ has been used in HPLC-ECD methods for general oxidative stress measurements.

We and others have synthesized a variety of C8-arylamine adducts of deoxyguanosine utilizing a Buchwald-Hartwig reaction as the key step. ${ }^{49-53}$ We report here an investigation of the chemical and electrochemical oxidation of a series of C8-arylamine adducts of deoxyguanosine. We find that the arylamine adducts have lower oxidation potentials than 8oxo-dG. Interestingly, not all of the $\mathrm{C} 8$-arylamine adducts undergo the expected overall twoelectron oxidation at neutral $\mathrm{pH}$.

\section{Experimental Section}

All commercially obtained chemicals were used as received unless otherwise specified. Nucleosides 6-10 were synthesized as previously described. ${ }^{50}$ Sodium hexachloroiridate was purchased from Alfa Aesar and used as received. Phosphate buffer ( $\mathrm{pH} 7.0)$ was purchased from Fisher Scientific. All reactions were performed in oven-dried glassware and under an argon atmosphere. ${ }^{1} \mathrm{H},{ }^{13} \mathrm{C}$ NMR and 2D-HMBC (heteronuclear multiple bond connectivity) data were recorded at 300, 400 and/or $600 \mathrm{MHz}$, respectively, in DMSO unless otherwise noted. High-resolution FAB mass spectra were obtained from the University of Notre Dame Mass Spectrometry Center using nitrobenzyl alcohol (NBA) as the matrix.

\section{Chemical oxidation of nucleosides $6 a$ and $7 a$}

Spiroiminodihydantoin 12-To a stirred solution of $\mathbf{6 a}(10 \mathrm{mg}, 0.022 \mathrm{mmol})$ in $50: 50 \mathrm{pH}$ 7 phosphate buffer and methanol $(2 \mathrm{~mL})$ was added sodium hexachloroiridate $(24 \mathrm{mg}, 0.044$ $\mathrm{mmol}$ ). The reaction was stirred at $10^{\circ} \mathrm{C}$ for $15 \mathrm{~min}$, then allowed to warm to room temperature. The spiroiminodihydantoin was purified by HPLC using water (solvent 1) and acetonitrile (solvent 2) on a C-18 reversed-phase column with UV detection. The solvent gradient was as follows: initially $99 \%$ solvent 1 , then 40 min linear gradient to $50 \%$ solvent 1,5 min isochratic at $50 \%$ solvent 1 , then a $5 \mathrm{~min}$ linear gradient to the initial conditions. The yield was $1 \mathrm{mg} .1 \mathrm{H}$ NMR (DMSO-d6) $\delta 9.05(\mathrm{dd}, J=4.2,1.7,1 \mathrm{H}), 8.81(\mathrm{~d}, J=8.3,1 \mathrm{H}), 7.93(\mathrm{~d}, J=8.9,1 \mathrm{H})$, $7.78(\mathrm{~d}, J=8.9,1 \mathrm{H}), 7.55(\mathrm{dd}, J=8.4,4.2,1 \mathrm{H}), 6.12-6.15(\mathrm{~m}, 1 \mathrm{H}), 4.12(\mathrm{~m}, 1 \mathrm{H}), 3.83(\mathrm{~s}, 3 \mathrm{H})$, 3.65 (m, 1H), 2.12-2.05 (m, 1H), 1.88-1.84 (m, 1H); 13C NMR (DMSO-d6) $\delta 181.02,171.61$, 148.00, 145.10, 134.09, 130.04, 129.21, 122.21, 120.70, 119.92, 113.83, 101.30, 87.61, 86.00, 84.06, 82.00, 81.11, 78.56, 70.72, 62.28, 34.99, 29.02; HRMS (FAB, NBA) m/z calcd for $\mathrm{C}_{21} \mathrm{H}_{21} \mathrm{~N}_{9} \mathrm{O}_{5}(\mathrm{M}+\mathrm{H})$ 480.166, found 480.124 .

Spiroiminodihydantoin 14-To a stirred solution of 7a $(10 \mathrm{mg}, 0.023 \mathrm{mmol})$ in $50: 50 \mathrm{pH}$ 7 phosphate buffer and methanol $(2 \mathrm{~mL})$ was added sodium hexachloroiridate $(26 \mathrm{mg}, 0.046$ $\mathrm{mmol})$. The reaction was stirred at $10^{\circ} \mathrm{C}$ for $15 \mathrm{~min}$, then allowed to warm to room temperature. The spirominodihydantoin was purified by HPLC using water (solvent 1) and acetonitrile (solvent 2) on a C-18 reversed-phase column with UV detection. The solvent gradient was as 
follows: initially $99 \%$ solvent 1 , then 40 min linear gradient to $50 \%$ solvent 1, 5 min isochratic at $50 \%$ solvent 1 , then a $5 \mathrm{~min}$ linear gradient to the initial conditions. The yield was $3 \mathrm{mg} .1 \mathrm{H}$ NMR (DMSO-d6) $\delta 8.69$ (br s, 1H), $7.64(\mathrm{~m}, 9 \mathrm{H}), 5.25$ (br s, 2H), $4.99(\mathrm{~m}, 1 \mathrm{H}), 4.25(\mathrm{~m}, 2 \mathrm{H})$, $3.80(\mathrm{~m}, 2 \mathrm{H}), 3.49(\mathrm{~m}, 4 \mathrm{H}), 2.37(\mathrm{~m}, 1 \mathrm{H}), 2.18(\mathrm{~m}, 1 \mathrm{H})$; 13C NMR (DMSO-d6) $\delta 181.08$, $172.78,166.15,139.50,128.92,126.73,123.01,122.98,86.559,84.676,83.98,82.143,71.59$, 61.57, 38.01; HRMS (FAB, NBA) m/z calcd for $\mathrm{C}_{22} \mathrm{H}_{22} \mathrm{~N}_{6} \mathrm{O}_{5}(\mathrm{M}+\mathrm{H}) 451.165$, found 451.193.

\section{Electrochemistry}

Electrochemical measurements (cyclic voltammetry, CV and square-wave voltammetry, SWV) were conducted with a CHI660A electrochemical workstation from $\mathrm{CH}$ Instruments equipped with a Faraday cage. The electrochemistry of the adducted nucleosides were investigated in both protic (phosphate buffer) and aprotic (acetonitrile) environments. The electrochemical cell was in a typical three-electrode configuration: working electrode which was either a $3 \mathrm{~mm}$ glassy carbon electrode (CHI104) or a $12 \mu \mathrm{m}$ carbon fiber ultramicroelectrode (CF-UME), $\mathrm{Pt}$ mesh counter electrode, $\mathrm{Ag} / \mathrm{AgCl}, 3 \mathrm{M} \mathrm{KCl}$ reference electrode for aqueous solutions (CHI111). In acetonitrile we employed a reference electrode based on an acrylic copolymer that was very stable over time and gave a lower background capacitance signal than the more conventional $\mathrm{Ag} / \mathrm{Ag}^{+}$reference. ${ }^{54}$ This is especially important when the reversibility of the studied compound is not obvious: if the nonfaradaic current is large, there is the risk for the electrochemical signal to get lost in the background. Glassy carbon disk working electrodes were polished with $0.25 \mu \mathrm{m}$ diamond paste from Buehler, sonicated in ethanol and water, dried in $\mathrm{N}_{2}$. CF-UMEs electrodes were polished with $0.05 \mu \mathrm{m}$ alumina from Buehler, sonicated in ethanol and water, dried in $\mathrm{N}_{2}$. For the aqueous studies the working electrode was the CF-UME since the glassy carbon electrode used in acetonitrile was not sensitive enough, due to the large non-faradaic current. All nucleoside solutions were $0.01-1 \mathrm{mM}$ in $500 \mathrm{mM} \mathrm{pH} 7.0$ phosphate buffer or $20 \mathrm{mM}$ potassium hexafluorophosphate $\left(\mathrm{KPF}_{6}\right)$ in acetonitrile. For all $\mathrm{SWV}$ measurements we used a frequency of $50 \mathrm{~Hz}$ and an amplitude of $50 \mathrm{mV}$.

\section{Results and Discussion \\ Electrochemical Oxidation}

The compounds included in this study (6-10) are shown in Figure 1 and were synthesized as previously described. ${ }^{50}$ This was accomplished via a Buchwald-Hartwig palladium-catalyzed cross-coupling reaction of a suitably protected 8-bromo-dG derivative with the desired arylamine. To improve the solubility of the substrates in acetonitrile, the ribose-protected nucleosides $(\mathbf{6 b}-\mathbf{1 0 b})$ were used. The half-wave potentials $\left(\mathrm{E}_{1 / 2}\right)$ for the $\mathrm{C} 8$-arylamine modified nucleosides are listed in Table 1 and have not been previously reported. The half-wave potential that we obtained for 8-oxo-dG (1) correlated very well with a recently reported value. 48

Although amines generally undergo irreversible oxidation due to facile side reactions and decomposition pathways of the aminyl radical cation, we found that all $\mathrm{C} 8$-arylamine adducts of deoxyguanosine exhibited quasi-reversible behavior in both aqueous buffer $(500 \mathrm{mM}, \mathrm{pH}$ 7.0 phosphate) and aprotic organic solvent (acetonitrile). It was possible to observe both the oxidation and the reduction peaks for the adducted nucleosides using cyclic voltammetry (CV). The more sensitive square-wave voltammetry (SWV) technique was required for 8-oxo-dG in order to distinguish the reduction current. Since the signal recorded with the SWV is a combination of both the anodic and the cathodic currents, it was possible to plot the cathodic peak current and its components. Similar to the results of Oliveira Brett and coworkers for 8oxo-G, ${ }^{47}$ we observed a distinct reduction component for 8 -oxo-dG as well (see Figure $\mathrm{S} 1$ in the Supporting Information section). The square-wave voltammogram for 8-oxo-dG in acetonitrile (Figure 2) showed that the process is still quasi-reversible in an aprotic medium. 
Cyclic voltammograms for the IQ and aminofluorene adducts ( 6 and 7 ) in both phosphate buffer and acetonitrile are shown in Figure 3 and are typical for the C8-arylamine adducts that we studied (see Figures S2-S4 in the Supporting Information for the other CVs). The amine oxidation is not completely electrochemically reversible for any of the compounds, indicating either slow electron-transfer kinetics or that the oxidation products undergo side reactions or decomposition pathways at a rate competitive with the CV experiment. The irreversibility was more pronounced in the aprotic environment, where the ratio between the cathodic reduction and anodic oxidation peaks were even lower. The separation between the anodic and cathodic peaks for the naphthylamine (8a), $p$-toluidine (9a) and aminofluorene (10a) adducted nucleosides in phosphate buffer are greater than $60 \mathrm{mV}$ (Table 1), the expected value for an ideally reversible one-electron process of a freely diffusing species, indicating that the redox reaction of the ArNH-dG/ArNH- $\mathrm{dG}^{*+}$ couple is only quasi-reversible in this medium. Interestingly, the peak separation was much less than $60 \mathrm{mV}$ for the IQ $(\mathbf{6 a}, 38 \mathrm{mV})$ and biphenyl adducts (7a, $48 \mathrm{mV}$ ), suggesting that their oxidation is based on a quasi-reversible two-electron oxidation ( $30 \mathrm{mV}$ is expected for an ideally reversible two-electron process).

The peak separation of C8-naphthylamine adducted nucleoside (8) was $72 \mathrm{mV}$, which is very close to the ideal value for a reversible one-electron oxidation and represents the point in our series where the oxidation mechanism goes from an overall two-electron process to oneelectron. The electrochemistry of this substrate was examined by chronoamperometry in order to firmly establish that substrates 8-10 $\left(\mathrm{E}_{\mathrm{pa}}-\mathrm{E}_{\mathrm{pc}}=72-89 \mathrm{mV}\right)$ are indeed one-electron oxidations rather than non-ideal two-electron oxidations. Bard and coworkers have developed a method to determine the diffusion coefficient $(D)$ for redox species without knowing the number of electrons $(n)$ that are involved in the redox process or the concentration $\left(c^{*}\right)$ of the electrochemically active species (8). ${ }^{55}$ According to this method, when a microdisk electrode is used, both the expression of the current at the microdisk $\left(i_{\mathrm{d}}(t)\right)$ and the steady state current $\left(i_{\mathrm{ss}}\right)$ are a function of $n$ and $c^{*}$, thus $i_{\mathrm{d}}(t) / i_{\mathrm{ss}}$ is not dependent on $n$ or $c^{*}$; when $i_{\mathrm{d}}(t) / i_{\mathrm{ss}} v s$. $t^{-1 / 2}$ is plotted in a chronoamperometry experiment, the expression of $D$ is dependent only on the size of the ultramicroelectrode and the slope $S$ of the plot $\left(D=\pi a^{2} / 16 S^{2}\right.$, where $a$ is the UME radius; see Figure S5 in the Supporting Information section). The diffusion coefficient $(D)$ of 8 was determined to be $3.8 \times 10^{-6} \mathrm{~cm}^{2} \mathrm{~s}^{-1}$ and by using the steady-state current value $\left(i_{\mathrm{sS}}=4 n F D c^{*} a=30 \mathrm{pA}\right)$ and the known concentration of the solution $\left(c^{*}=0.41 \mathrm{mM}\right)$, the number of electrons $(n)$ involved in the oxidation of $\mathbf{8}$ in buffer was calculated to be one. This finding reinforces the $\mathrm{CV}$ data that the quasi-reversible oxidation of the series of $\mathrm{C} 8$-arylamine adducted nucleoside 6-10 can occur by either a one- or two-electron process.

For our $\mathrm{CV}$ experiments in acetonitrile, the perfectly reversible couple ferrocenium/ferrocene $\left(\mathrm{Fc}^{+/ 0}\right)$ displayed a peak separation of $100 \mathrm{mV}$. The deviation of this value from the theoretical value of $60 \mathrm{mV}$ is due to two main reasons: (i) the theory has been developed for perfect conductors (metals such as Au or Pt), and the peak separation is always larger at electrodes manufactured from materials that present slower kinetics (e.g., glassy carbon); 56 and (ii) the measurements are performed in an organic solution (acetonitrile) that presents higher resistance than aqueous solutions and consequently causes the peak separation to increase. ${ }^{57}$ The peak separation values for all substrates in acetonitrile (Table 1) are greater than $150 \mathrm{mV}$ and suggest that the redox reaction is a quasi-reversible one-electron process.

\section{Chemical Oxidation}

While the electrochemical oxidation gives valuable information regarding the mechanism of the redox process, it does not provide an opportunity for the structural analysis of products derived from the oxidation reaction. We therefore examined the chemical oxidation of the C8arylamine modified nucleosides in order to identify oxidation products. Since there is wide human exposure to IQ through diet, we were particularly interested in the C8-IQ adduct (6) 
whose $\mathrm{E}_{1 / 2}$ is the same as 8-oxo-dG and undergoes a two-electron oxidation. The chemical oxidation was carried out under conditions similar to those developed by Burrows using with $\mathrm{Na}_{2} \mathrm{IrCl}_{6}$ as the oxidant at $4^{\circ} \mathrm{C}$. Due to solubility limitation of $\mathbf{6 a}$, we used a 1:1 mixture of 50 $\mathrm{mM}, \mathrm{pH} 7$ phosphate buffer and methanol as the solvent. The oxidation of $\mathbf{6 a}$ initially gave one major product, which was unstable and several minor products. The major product had a longer retention time when analyzed by reversed-phase HPLC than the starting material 6a; based on LC-ESI-MS analysis, which gave an $m / z$ [M+H] of 494.1, the initial two-electron oxidation product was assigned as the 5-methoxy derivative $\mathbf{1 1}$ (Scheme 3). When the reaction was warmed to room temperature, the initially formed product assigned as $\mathbf{1 1}$ was converted to two new rearrangement products, the major product possessed a mass consistent with the spiroiminodihydantoin 12 observed as a near equal mixture of two diastereomers, and the minor product was consistent with the guanidinohydantoin 13 (Scheme 3). The rearrangement products $(\mathbf{1 2}$ and $\mathbf{1 3})$ are similar to those previously characterized from the chemical oxidation of 8-oxo-dG. ${ }^{18,58}$ The chemical oxidation of the C8-(4-aminobiphenyl) adduct 7a gave similar results, except the analogous spiroiminodihydantoin was the only product observed.

The diastereomers of the spiroiminodihydantoin (14) derived the 4-aminobiphenyl adduct were examined by one and two-dimensional NMR spectroscopy. The ribose and aromatic protons were assigned via COSY spectrum. The proton assignments greatly aided in the assignments of the carbon resonances, which was done by ${ }^{1} \mathrm{H}^{13} \mathrm{C}$ heteronuclear correlation (HMBC). McCallum and Foote have assigned the HMBC spectra of a spiroiminodihydantoin product derived from the oxidation of 8-oxo-dG (2) and observed a three-bond ${ }^{1} \mathrm{H}_{-}{ }^{13} \mathrm{C}$ correlation between the anomeric proton $\left(\mathrm{H} 1^{\prime}\right)$ and the quarternary spiro carbon at $80 \mathrm{ppm}$ and the urea carbonyl carbon at $154 \mathrm{ppm} .{ }^{15}$ The HMBC spectrum of 14 (Figure 4) showed a clear threebond coupling between the anomeric proton $\left(\mathrm{H}-1^{\prime}, 5.01 \mathrm{ppm}\right)$ and the quaternary spiro center at $82 \mathrm{ppm}$. Our spectral assignments are in good agreement with those reported for $\mathbf{2}$.

A possible mechanism for the oxidation of the $\mathrm{C} 8$-arylamine modified deoxyguanosines is shown in Scheme 4 and is similar to that proposed for 8-oxo-dG oxidation. ${ }^{20,21}$ Oxidation gives the corresponding $\mathrm{C} 8$-arylamine adducted guanosine radical cation, which upon deprotonation leads to the radical. Oxidation of the radical provides the guanosine cation, which can be stabilized by the $\mathrm{C} 8$-amino group; this intermediate can reversibly add hydroxide to the C5 position. Rearrangement of this intermediate then follows the same course as in Scheme 1 for 8-oxo-dG and gives the arylamine analogues of the spiroiminodihydantoin (4) and guanidinohydantoin (5) products (Scheme 2). Johnson observed that the oxidative rearrangement of the $\mathrm{C} 8$-aminofluorene adduct in air proceed slowly at neutral $\mathrm{pH}$ but is accelerated under alkaline conditions. To account for the $\mathrm{pH}$ dependence it was proposed that deprotonation occurs to the $\mathrm{C} 8$-modified guanosine anion, which is then oxidized to the corresponding radical by molecular oxygen. ${ }^{34}$ The guanosine radical can undergo radical recombination with superoxide to give the $\mathrm{C} 5$-hydroperoxide after protonation, which can then exchange with water to give the rearrangement precursor.

We found that the chemical oxidation of the C8-naphthylamine adduct (8a) with $\mathrm{Na}_{2} \mathrm{IrCl}_{6}$ was sluggish even with excess oxidant and warming the reaction to room temperature; similar behavior was observed for the aminofluorene adduct (10a). This is in contrast to the chemical oxidation of 6a, which has an electrochemical oxidation potential higher than 8a and 10a. The difference in reactivity of $\mathbf{8 a}$ and $\mathbf{1 0 a}$ probably lies in the mechanism of the redox as gleaned from the electrochemical oxidations. The mechanism of the $\mathrm{C} 8$-arylamine adducts that gave rearrangement products upon treatment with $\mathrm{Na}_{2} \mathrm{IrCl}_{6}(\mathbf{6 a}, 7 \mathbf{a})$ involved a two-electron oxidation. The aminofluorene and naphthylamine adducts undergo a one-electron oxidation and rearrangement products were not readily produced upon chemical oxidation with $\mathrm{Na}_{2} \mathrm{IrCl}_{6}$. Electrochemical oxidations often parallel chemical oxidations with agents that work by an outer-sphere electron-transfer mechanism. With regard to the mechanism in Scheme 4, 
it would appear that the deprotonation of the radical cation or further oxidation of the radical is slow for substrates $\mathbf{8 a}$ and $\mathbf{1 0 a}$, while being fast compared to the initial one-electron oxidation for $6 \mathbf{a}$ or 7a. It is difficult to rationalize such a dramatic difference based on the nature of the aryl group. When the electrochemical oxidation of $\mathbf{8 a}$ and $\mathbf{1 0 a}$ was measured at $\mathrm{pH} 9.0$, the oxidation potential shifted -160 and $-180 \mathrm{mV}$, respectively; however, the anodic and cathodic peak separation did not change, indicating that the mechanism still involved a one-electron oxidation.

A plausible explanation for the different mechanisms may involve the conformation of the C8arylamine group relative to the guanosine ring. The $\mathrm{C} 8$-arylamine substituent would have the greatest influence on the redox behavior of the modified guanosine when they are co-planar. Rotation about the C $8-N^{8}$ bond would greatly reduce the electronic interaction between the arylamine adduct and the guanosine ring. In such a case, the oxidation may occur on the arylamine moiety. Since the potentially acidic proton resides on the guanosine ring, the aminyl radical cation resulting from the twisted conformation (15, Figure 5) cannot undergo deprotonation and further oxidation. In the coplanar conformation, this radical cation is an alternative resonance form of radical cation 16, which leads to the oxidative rearrangement products. Depending on the stability and reactivity of the aminyl radical cation 16, it can undergo decomposition and side-reactions or undergo one-electron reduction back to the original closed-shell species giving a quasi-reversible redox couple observed in the cyclic voltammograms.

The adducted deoxyguanosines that exhibit a two-electron redox couple (6a and 7a), either undergo initial oxidation on the guanine ring or exist in a coplanar conformation so that the oxidation product is delocalized. In such a case, the radical cation can undergo deprotonation and a second one-electron oxidation eventually leading to the oxidative rearrangement products 12 and 13, and 14. This mechanistic proposal suggests that further oxidation of C8-arylamine adducts and subsequent rearrangement to potentially more mutagenic products will be highly dependent upon the adduct conformation. This scenario is particularly intriguing for the C8IQ adduct given our previous results that suggest the specific conformation of the adduct in DNA is highly dependent on local sequence context. ${ }^{50,59}$ Because of widespread exposure, arylamine adducts are likely to play an important role in human cancers. Oxidation products derived from C8-arylamine adducts are likely to play a role in the overall tumorigenic properties of arylamine and it is therefore important to understand chemistry of this process.

\section{Potential Biological Implications}

The oxidation potential of the $\mathrm{C} 8$-arylamine adducts indicate that they can support electron transfer to a guanine cation radical by long-distance electron transfer. ${ }^{19}$ In the case of the C8IQ and aminobiphenyl adducts, the resulting arylamine-dG cation radical is susceptible to further oxidation and subsequent rearrangement to the corresponding spiroiminodihydantoin and guanidinohydantoin species. These rearrangement products are likely to be highly mutagenic. C8-Arylamine adducts are potent inducers of one- and two-base frameshift deletions. The mechanism of the frameshift involves a syn-conformation of the modified guanine with the C8-arylamine group intercalated into the DNA helical stack. ${ }^{37}$ This places the modified dG into an extrahelical loop; this conformation leads to misalignment of the template and primer strands which leads to frameshift mutations. Upon oxidative rearrangement, the dramatic change in geometry of the modified base from a two-dimensional planar guanine to a three-dimensional spiroiminodihydantoin ring system will strongly favor the base-displaced intercalated conformation, and consequently may lead to a greater proportion of frameshift mutations. The other $\mathrm{C} 8$-arylamine adducts we examined (2aminofluorene, 2-naphthylamine and p-toluidine) will also support electron transfer to a guanine cation radical; however, the further oxidation of the resulting C8-arylamine cation 
radical is significantly less favorable. As a result, these species could be reduced by glutathione or similar related reductants back to the original closed-shell C8-arylamine adduct. In this regard, such adducts may be protective of further oxidative damage to DNA in the vicinity of the $\mathrm{C} 8$-arylamine adduct.

The oxidation potential of the C8-arylamine adducts are likely to be different in DNA than in nucleosides. Solvation, electrostatics, base-stacking and other local sequence effects can play significant roles in tuning the oxidation potential of the C8-modified guanine. ${ }^{60,61} \mathrm{We}$ have proposed that the conformation of the $\mathrm{C} 8$-arylamine adduct controls the oxidation mechanism (one- versus two-electron oxidation). The high-resolution NMR structures of oligonucleotide duplexes containing the C8-dG adducts of IQ, PhIP, 1-aminopyrene (AP), 4-aminobiphenyl, and 2-aminofluorene (AF) have been reported. ${ }^{59,62-67}$ NMR analysis have shown that the C8-IQ, PhIP and AP adducts adopt a base-displaced intercalated conformation in a 5'-CGC-3' ( $\underline{\mathbf{G}}$ is the $\mathrm{C} 8$-modified guanine) local sequence. Using the coordinates from these structures, the angles between the best-fit plane through the ring atoms of the modified guanine and the best-fit plane comprised of the arylamine ring atoms were calculated with the CrytalMaker software package (v. 6.3.10). In the case of the PhIP, AF and AP-modified duplexes, the angle between the modified guanine and the arylamine were calculated to be $\sim 36^{\circ}, 62,64,65$ while the same angle for the IQ adduct was considerably greater, $52^{\circ} .59$ The adduct was found to prefer a base-displaced intercalated conformation for these duplexes. The intercalated C8-AF adduct opposite a two-base deletion was also examined and this angle between the guanine and $\mathrm{AF}$ ring system was $\sim 21^{\circ} .{ }^{68}$ The angle between the modified guanine and the AF-group for the groove-bound conformation was $\sim 49^{\circ} .66$ This analysis indicates that the specific conformation of the adducts depending on the local sequence may influence the susceptibility of the C8-arylamine adducts toward oxidation. The base-displaced intercalated conformation has a relatively modest twisting of the $\mathrm{C} 8-N^{8}$-bond for the AF, AP and PhIP adducts. This indicates that this conformation may be easier to oxidize than the groove-bound conformation, which has a larger degree of non-planarity.

\section{Conclusions}

The C8-arylamine adducts of dG undergo either a two-electron (6 and 7 ) or a one-electron (8, 9, 10) electrochemical oxidation. Their half-wave potentials situate them in an energetically favorable position to transfer an electron to a guanosine cation radical. ${ }^{19}$ The chemical oxidation of C8-arylamine adducts correlates with the electrochemical oxidations. The nucleosides that undergo a two-electron oxidation ( 6 and 7$)$ rearrange to give mainly a spiroiminodihydantoin. This oxidative rearrangement chemistry observed for the 8-arylamine adducts parallels that of 8-oxo-dG, which has been well characterized.

\section{Supplementary Material}

Refer to Web version on PubMed Central for supplementary material.

\section{Acknowledgements}

Partial support of this work was provided by a center grant from the National Institute of Environmental Health Sciences (ES000267). JSS acknowledges support from an NIEHS pre-doctoral traineeship (ES007028). MC was supported by a Vanderbilt Discovery Grant. We are grateful to Professor Suse Broyde and Dr. Lihua Wang for the coordinates of the C8-AF modified duplexes.

\section{References}

1. Cooke MS, Evans MD, Dizdaroglu M, Lunec J. FASEB J 2003;17:1195-1214. [PubMed: 12832285] 
2. Burrows CJ, Muller JG, Kornyushyna O, Luo WC, Durante V, Leipold MD, David SS. Environ Health Perspect 2003;110(Suppl 5):713-717. [PubMed: 12426118]

3. Cadet J, Delatour T, Douki T, Gasparutto D, Pouget JP, Ravanat JL, Sauvaigo S. Mutat Res 1999;424:921. [PubMed: 10064846]

4. Cadet J, Douki T, Gasparutto D, Ravanat JL. Mutat Res 2003;531:5-23. [PubMed: 14637244]

5. Bjelland S, Seeberg E. Mutat Res 2003;531:37-80. [PubMed: 14637246]

6. Neeley WL, Essigmann JM. Chem Res Toxicol 2006;19:491-607. [PubMed: 16608160]

7. Shibutani S, Takeshita M, Grollman AP. Nature 1991;349:431-434. [PubMed: 1992344]

8. Brieba LG, Eichman BF, Kokoska RJ, Doublie S, Kunkel TA, Ellenberger T. EMBO J 2004;23:34523461. [PubMed: 15297882]

9. Gannett PM, Sura TP. Chem Res Toxicol 1993;6:690-700. [PubMed: 8292748]

10. Kouchakdjian M, Bodepudi V, Shibutani S, Eisenberg M, Johnson F, Grollman AP, Patel DJ. Biochemistry 1991;30:1403-1412. [PubMed: 1991121]

11. Haracska L, Yu SL, Johnson RE, Prakash L, Prakash S. Nat Genet 2000;25:458-461. [PubMed: 10932195]

12. Tretyakova NY, Niles JC, Burney S, Wishnok JS, Tannenbaum SR. Chem Res Toxicol 1999;12:459_ 466. [PubMed: 10328757]

13. Joffe A, Geacintov NE, Shafirovich V. Chem Res Toxicol 2003;16:1528-1538. [PubMed: 14680366]

14. Crean C, Geacintov NE, Shafirovich V. Angew Chem Int Ed Engl 2005;44:5057-5060. [PubMed: 16013075]

15. McCallum JEB, Kuniyoshi CY, Foote CS. J Am Chem Soc 2004;126:16777-16782. [PubMed: 15612716]

16. Suzuki T, Masuda M, Friesen MD, Ohshima H. Chem Res Toxicol 2001;14:1163-1169. [PubMed: 11559029]

17. Sugden KD, Campo CK, Martin BD. Chem Res Toxicol 2001;14:1315-1322. [PubMed: 11559048]

18. Luo W, Muller JG, Rachlin EM, Burrows CJ. Chem Res Toxicol 2001;14:927-938. [PubMed: 11453741]

19. Hall DB, Holmlin RE, Barton JK. Nature 1996;382:731-735. [PubMed: 8751447]

20. Goyal RN, Jain N, Garg DK. Bioelectrochem Bioenerg 1997;43:105-114.

21. Kahn K, Serfozo P, Tipton PA. J Am Chem Soc 1997;119:5435-5442.

22. Kornyushyna O, Berges AM, Muller JG, Burrows CJ. Biochemistry 2002;41:15304-15314. [PubMed: 12484769]

23. Leipold M, Muller JG, Burrows CJ, David SS. Biochemistry 2000;39:14984-14992. [PubMed: 11101315]

24. Leipold M, Workman H, Muller JG, Burrows CJ, David SS. Biochemistry 2003;42:11373-11381. [PubMed: 14503888]

25. Hailer MK, Slade PG, Martin BD, Rosenquist TA, Sugden KD. DNA Repair 2005;4:41-50. [PubMed: 15533836]

26. Hailer MK, Slade PG, Martin BD, Sugden KD. Chem Res Toxicol 2005;18:1378-1383. [PubMed: 16167829]

27. Duarte V, Muller JG, Burrows CJ. Nucl Acids Res 1999;27:496-502. [PubMed: 9862971]

28. Kornyushyna O, Burrows CJ. Biochemistry 2003;42:13008-13018. [PubMed: 14596616]

29. Henderson PT, Delaney JC, Muller JG, N WL, Tannenbaum SR, Burrows CJ, Essigmann JM. Biochemistry 2003;42:9257-9262. [PubMed: 12899611]

30. Durandin A, Jia L, Crean C, Kolbanovskiy A, Ding S, Shafirovich V, Broyde S, Geacintov NE. Chem Res Toxicol 2006;19:908-913. [PubMed: 16841958]

31. Jia J, Shafirovich V, Shapiro R, Geacintov NE, Broyde S. Biochemistry 2005;44:6043-6051. [PubMed: 15835893]

32. Jia L, Shafirovich V, Shapiro R, Geacintov NE, Broyde S. Biochemistry 2005;44:13342-13353. [PubMed: 16201759]

33. Shibutani S, Gentles RG, Iden CR, Johnson F. J Am Chem Soc 1990;112:5667-5668.

J Am Chem Soc. Author manuscript; available in PMC 2008 August 27. 
34. Johnson, F. Studies in Natural Products Chemistry. Rahman, A., editor. 8. Elsevier Science Publishers; Amsterdam: 1991. p. 373-394.

35. Johnson F, Huang CY, Yu PL. Environ Health Perspect 1994;102(suppl 6):143-149. [PubMed: 7889837]

36. Heflich RH, Neft RE. Mutat Res 1994;318:73-174. [PubMed: 7521935]

37. Hoffmann GR, Fuchs RPP. Chem Res Toxicol 1997;10:347-359. [PubMed: 9114969]

38. Kim D, Guengerich FP. Ann Rev Pharm Toxicol 2005;45:27-49.

39. Hecht SS. Environ Mol Mutagen 2002;39:119-126. [PubMed: 11921179]

40. Turesky RJ, Freeman JP, Holland RD, Nestorick DM, Miller DW, Ratnasinghe RD, Kadlubar FF. Chem Res Toxicol 2003;16:1162-1173. [PubMed: 12971805]

41. Turesky RJ. Drug Metab Rev 2002;34:625-650. [PubMed: 12214671]

42. Sugimura T. Carcinogenesis 2000;21:387-395. [PubMed: 10688859]

43. Schut HA, Snyderwine EG. Carcinogenesis 1999;20:353-368. [PubMed: 10190547]

44. Sugimura T. Mutat Res 1997;376:211-219. [PubMed: 9202758]

45. Bi SP, Liu B, Fan FRF, Bard AJ. J Am Chem Soc 2005;127:3690-3691. [PubMed: 15771491]

46. Goyal RN, Puri BK, Jain N. J Chem Soc Perkin Trans 2001;2:832-837.

47. Oliveira Brett AM, Piedade JAP, Serrano SHP. Electroanalysis 2000;12:969-973.

48. Langmaier J, Samec Z, Samcova E. Electroanalysis 2003;15:1555-1560.

49. Wang Z, Rizzo CJ. Org Lett 2001;3:565-568. [PubMed: 11178826]

50. Elmquist CE, Stover JS, Wang Z, Rizzo CJ. J Am Chem Soc 2004;126:11189-11201. [PubMed: 15355100]

51. Gillet LCJ, Alzeer J, Scharer OD. Nucl Acids Res 2005;33:1961. [PubMed: 15814813]

52. Gillet LCJ, Scharer OD. Org Lett 2002;4:4205-4208. [PubMed: 12443059]

53. Lakshman MK. Curr Org Synth 2005;2:83-112.

54. Ciobanu M, Wilburn JP, Lowy DA. Electroanalysis 2004;16:1351-1358.

55. Denuault G, Mirkin MV, Bard AJ. J Electroanal Chem Interfac Electrochem 1991;308:27-38.

56. Orwa JO, Prawer S, Jamieson DN, Peng JL, McCallum JC, Nugent KW, Li YJ, Bursill LA, Withrow SP. J Appl Phys 2001;90:3007-3018.

57. Davis JJ, Hill HAO, Bond AM. Coord Chem Rev 2000;200-202:411-442.

58. Luo W, Muller JG, Rachlin EM, Burrows CJ. Org Lett 2000;2:613-616. [PubMed: 10814391]

59. Wang F, De Muro NE, Elmquist CE, Stover JS, Rizzo CJ, Stone MP. J Am Chem Soc 2006;128:10085-10095. [PubMed: 16881637]

60. Saito I, Nakamura T, Nakatani K, Yoshioka Y, Yamaguchi K, Sugiyama H. J Am Chem Soc 1998;120:12686-12687.

61. Margolin Y, Cloutier JF, Shafirovich V, Geacintov NE, Dedon PC. Nat Chem Biol 2006;2:365-366. [PubMed: 16751762]

62. Brown K, Hingerty BE, Guenther EA, Krishnan VV, Broyde S, Turteltaub KW, Cosman M. Proc Natl Acad Sci USA 2001;98:8507-8512. [PubMed: 11438709]

63. Cho BP, Beland FA, Marques MM. Biochemistry 1992;31:9587-9602. [PubMed: 1327120]

64. Gu Z, Gorin AA, Krishnasami R, Hingerty BE, Basu AK, Broyde S, Patel DJ. Biochemistry 1999;38:10843-10854. [PubMed: 10451381]

65. Mao B, Hingerty BE, Broyde S, Patel DJ. Biochemistry 1998;37:81-94. [PubMed: 9425028]

66. Mao B, Hingerty BE, Broyde S, Patel DJ. Biochemistry 1998;37:95-106. [PubMed: 9425029]

67. Patel DJ, Mao B, Gu Z, Hingerty BE, Gorin A, Basu AK, Broyde S. Chem Res Toxicol 1998;11:391407. [PubMed: 9585469]

68. Mao B, Gorin A, Gu Z, Hingerty BE, Broyde S, Patel DJ. Chem Res Toxicol 1997;36:14479-14490. 
<smiles>[R]n1c(Nc2nc3c(=O)[nH]c(N)nc3n2C)nc2c3cccnc3ccc21</smiles>

6<smiles>[R]n1c(Nc2ccc3ccccc3c2)nc2c(=O)[nH]c(N)nc21</smiles><smiles>[R]n1c(Nc2ccc3c(c2)-c2ccccc2C3)nc2c(=O)[nH]c(N)nc21</smiles>

10<smiles>[R]n1c(Nc2ccc(-c3ccccc3)cc2)nc2c(=O)[nH]c(N)nc21</smiles><smiles>[R]n1c(Nc2ccc(C)cc2)nc2c(=O)[nH]c(N)nc21</smiles><smiles>CC1CC(C)C(CO)O1</smiles>

b<smiles>CC[C@H]1C[C@@H]2O[Si](C(C)C)(C(C)C)O[Si](C(C)C)(C(C)C)OC[C@H]2O1</smiles>

Figure 1.

C8-Arylamine adducted deoxyguanosines investigated; in acetonitrile the 3',5'-deoxyribose protecting group was retained for solubility purposes. 


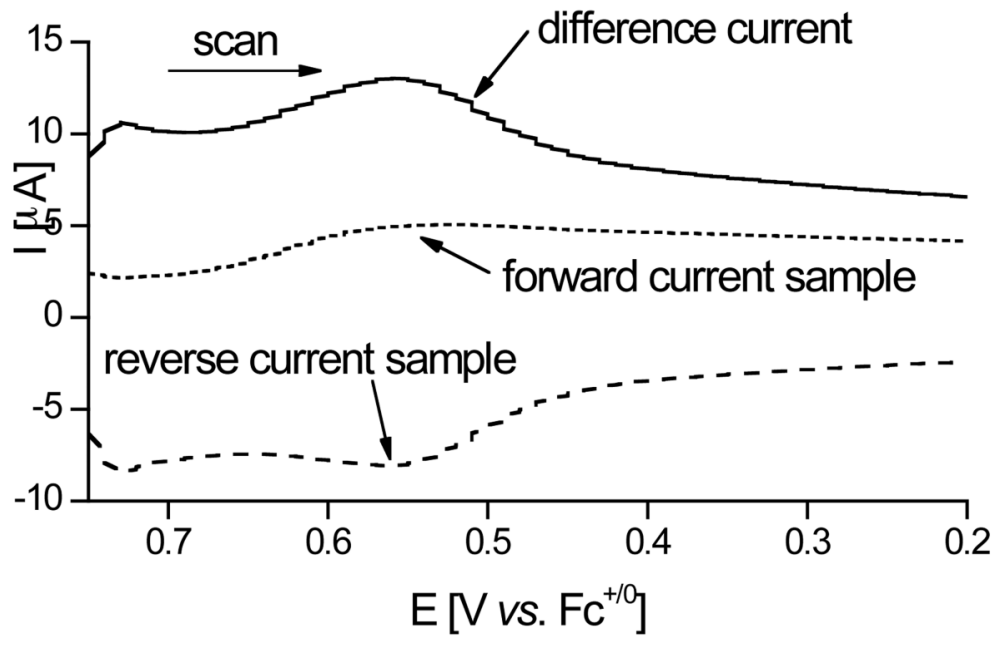

Figure 2.

Square-wave voltammogram of 8-oxo-dG in anhydrous acetonitrile, $3 \mathrm{~mm}$ glassy carbon working electrode: reduction current (solid line, difference current) and its components, the anodic oxidation (dotted line, forward current sample) and the cathodic reduction (dashed line, reverse current sample) currents. 

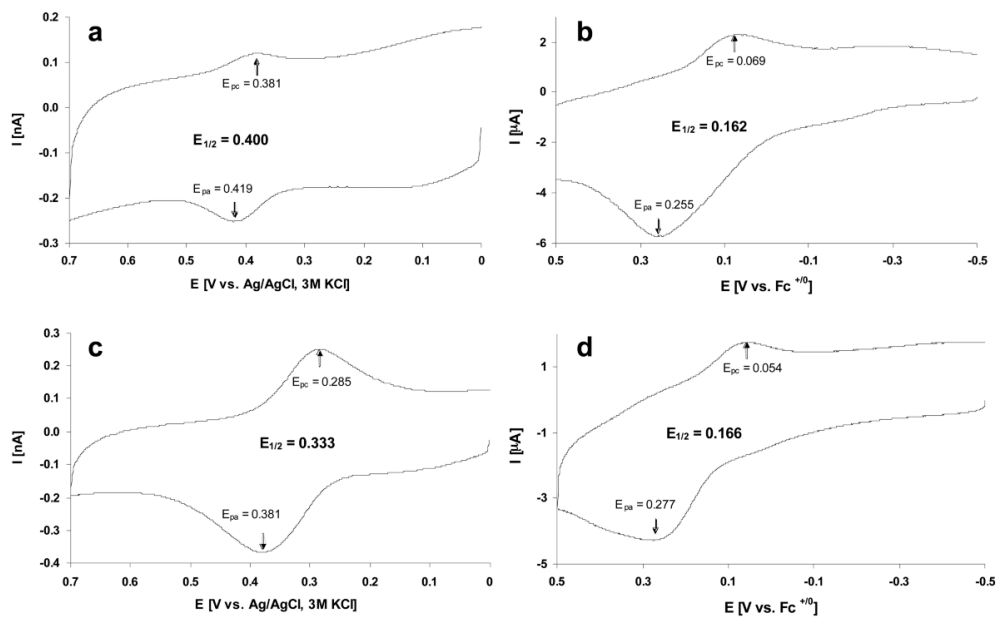

Figure 3.

Cyclic voltammograms of: (a) dG-C8-IQ in phosphate buffer; (b) dG-C8-IQ in acetonitrile; (c) AF-dG in phosphate buffer; (d) AF-dG in acetonitrile. The scan rate is in all cases 0.25 $\mathrm{V} \cdot \mathrm{s}^{-1}$; the working electrode was a $12 \mu \mathrm{m}$ carbon fiber ultramicroelectrode (CF-UME) in phosphate buffer and a $3 \mathrm{~mm}$ glassy carbon in acetonitrile. 
<smiles>CC1(N2C(Nc3ccc(-c4ccccc4)cc3)=NC(=O)C23N=C(N)NC3=O)CC(O)C(CO)O1</smiles>

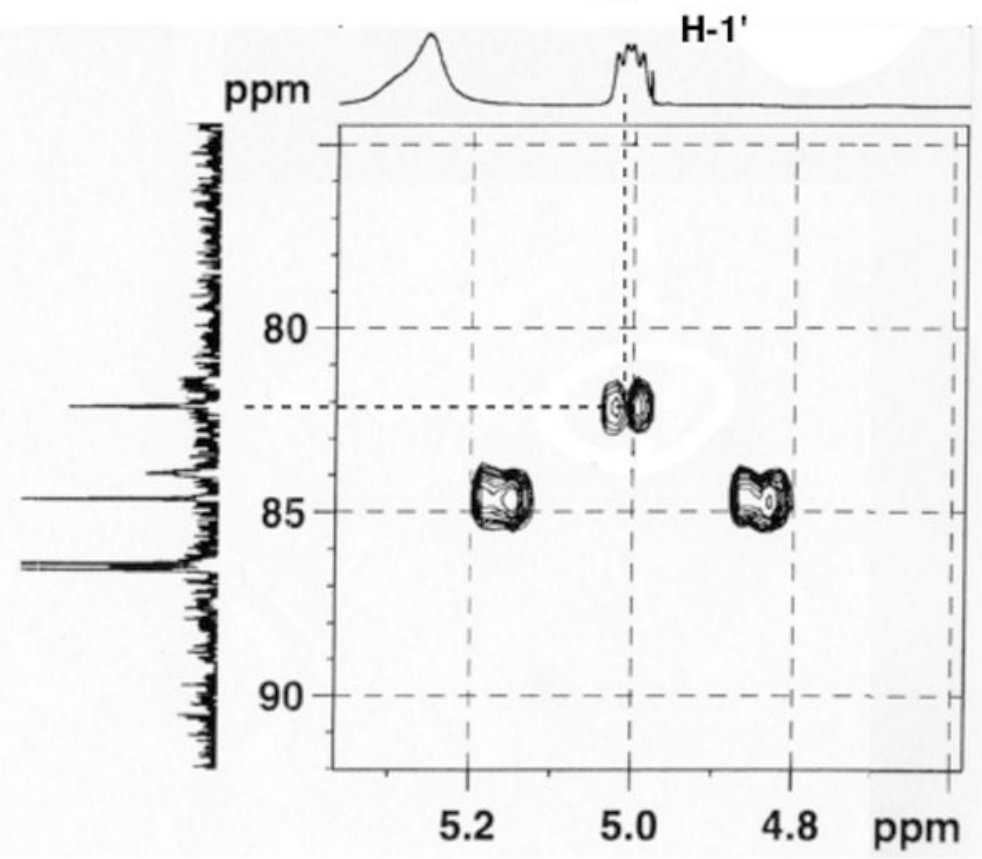

Figure 4.

HMBC spectrum of the spiroiminodihydantoin (14) derived from the chemical oxidation of $7 \mathbf{a}$. 
<smiles>Nc1nc2c(nc([NH+]([18F])[18F])n2[Tl])c(=O)[nH]1</smiles>

15<smiles></smiles>

16

Figure 5.

One-electron oxidation products 


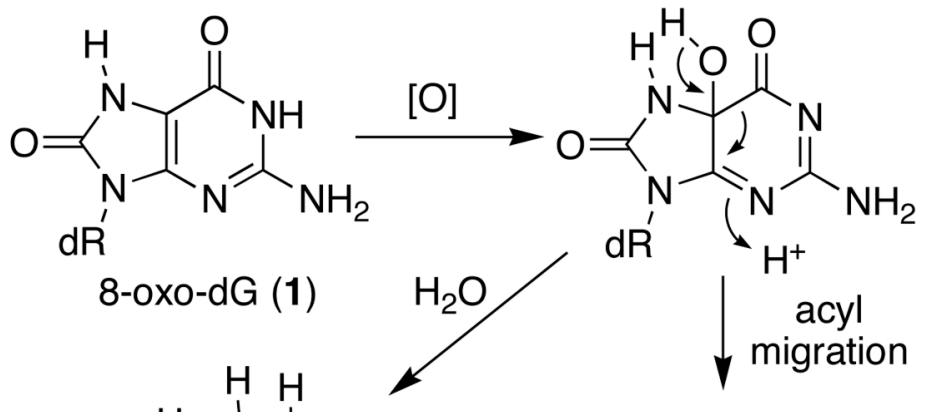

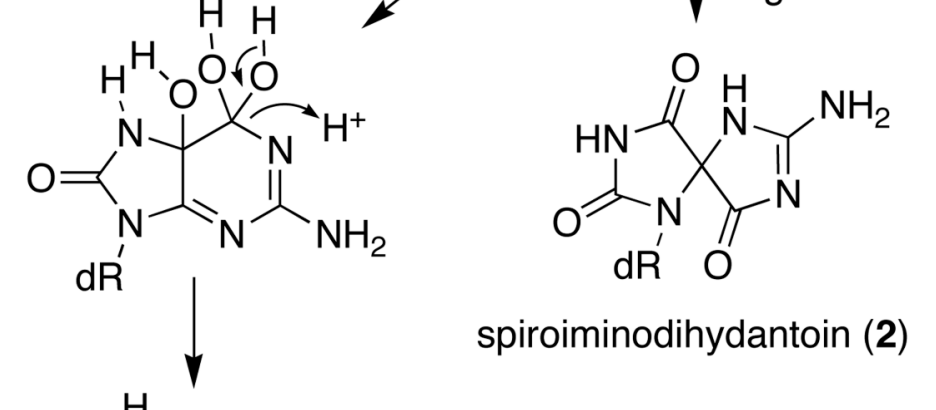<smiles>NC(=[NH2+])/N=C1\N([Tl])C(=O)NC1(O)C(=O)[O-]</smiles>

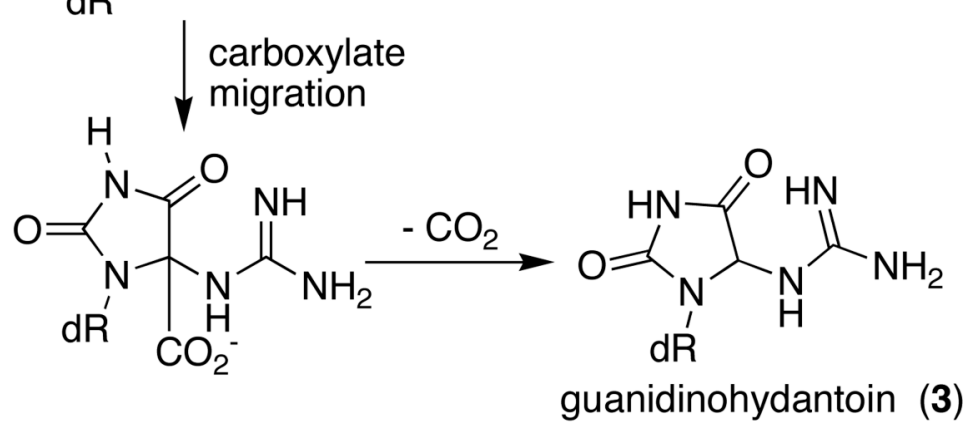

Scheme 1. 
<smiles>Nc1nc2c(nc(N[Al])n2[Tl])c(=O)[nH]1</smiles>

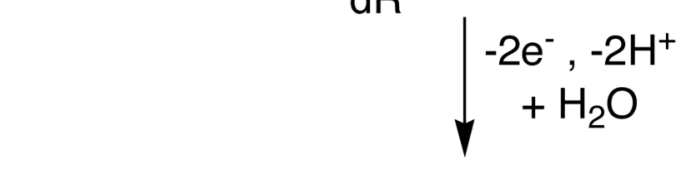<smiles>[Z9]N1C(N[Al])=NC(=O)C12N=C(N)NC2=O</smiles>

Scheme 2. 

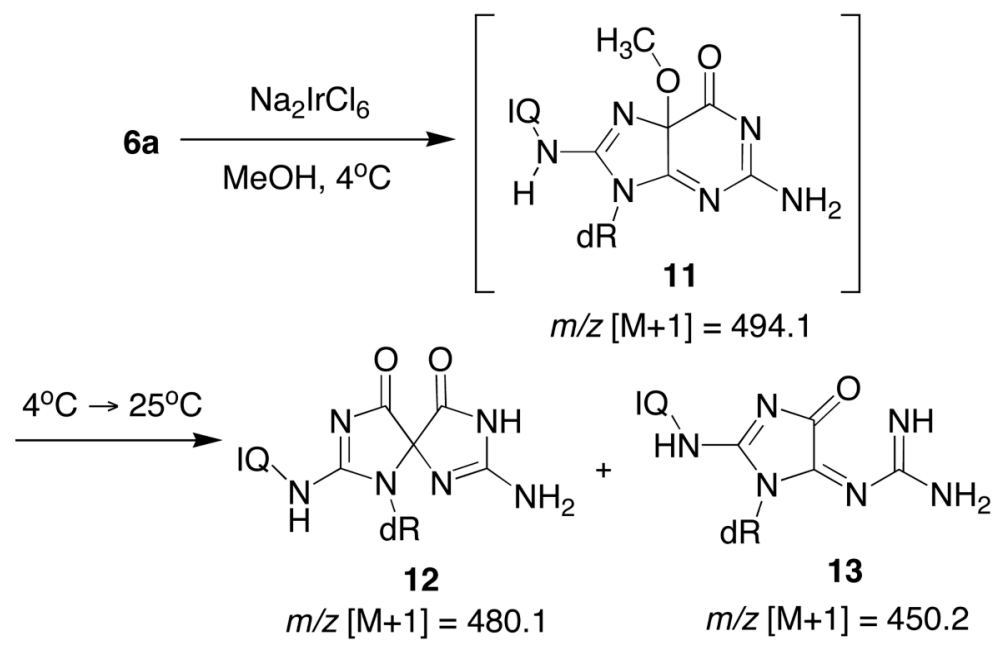

Scheme 3 . 
<smiles>Nc1nc2c(nc(N[Ga])n2[Tl])c(=O)[nH]1</smiles><smiles></smiles><smiles>COc1nc(N)nc2c1nc(N[Al])n2[Tl]</smiles><smiles>NC1=NC(=O)C2N=C(N[Al])N([Tl])C2=N1</smiles><smiles>NC1=NC(=O)C2(O)N=C(N[Al])N(P)C2=N1</smiles>
$+e^{-\uparrow}-e^{-}$

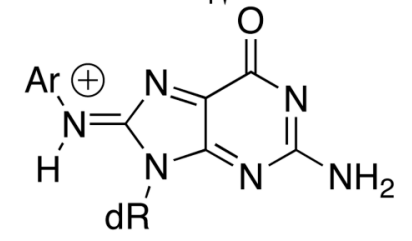

Scheme 4. 


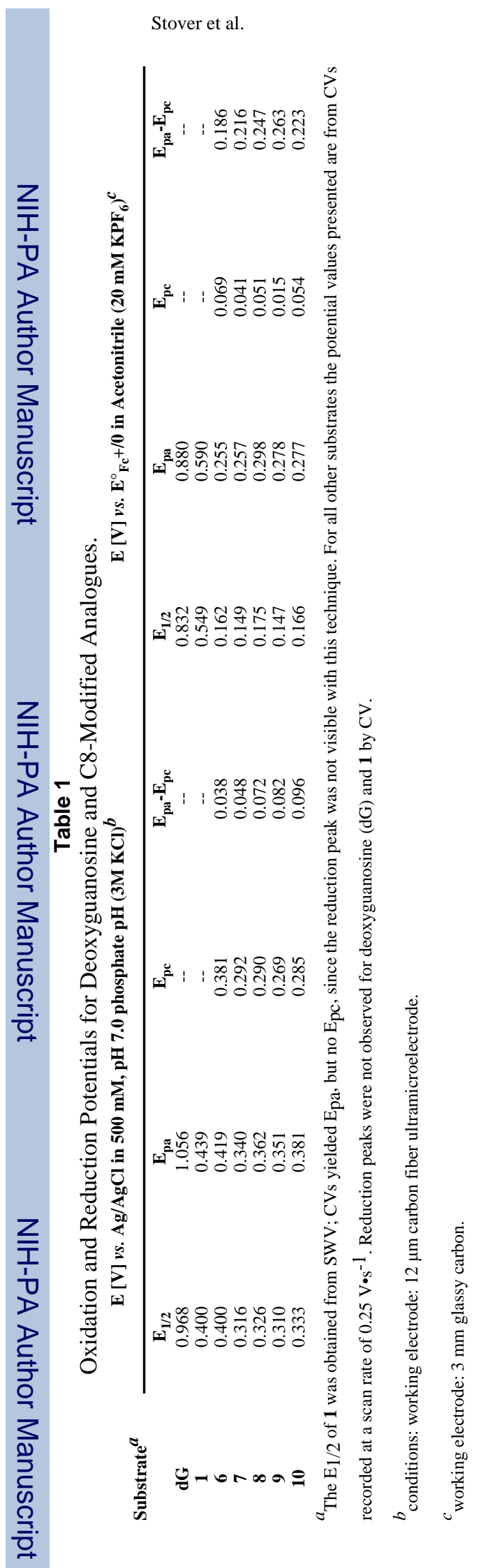

J Am Chem Soc. Author manuscript; available in PMC 2008 August 27. 